\title{
Original article (short paper) \\ Oxygen uptake in water polo, comparison and agreement in cycle ergometer and eggbeater kick: A pilot study
}

\author{
Ligia Ignêz Engelmann \\ Giane Veiga Liedtke \\ Flávio de Souza Castro \\ Universidade Federal do Rio Grande do Sul, Porto Alegre, RS, Brasil
}

\begin{abstract}
The aim of this study was to compare and verify the agreement of maximal oxygen uptake $\left(\mathrm{VO}_{2 \max }\right)$ values obtained from tests on land and in water. Twelve recreational water polo players $(30.5 \pm 7.7$ years; $79.2 \pm 7.2 \mathrm{~kg}$ body mass; $179.1 \pm 5.9 \mathrm{~cm}$ height) were assessed in two phases: (1) in laboratory with maximal test on a cycle ergometer and (2) in a swimming pool with maximal test in eggbeater kick. Maximum values obtained in the two tests (respectively, cycle ergometer, and eggbeater kick: $\mathrm{VO}_{2 \max }=40.2 \pm 2.7 \mathrm{ml} \cdot \mathrm{kg}^{-1} \cdot \mathrm{min}^{-1}$ and $38.4 \pm 5.7 \mathrm{ml} \cdot \mathrm{kg}^{-1} \cdot \mathrm{min}^{-1} ; \mathrm{RER}=1.17 \pm 0.08$ and 1.19 $\pm 0.12 ; \mathrm{HR}_{\max }=181.4 \pm 11.7 \mathrm{bpm}$ and $179 \pm 11.7 \mathrm{bpm} ; \mathrm{IEP}=20$ and 20) did not show significant differences. According to the Bland-Altman analyses, there were acceptable limits of agreement between the two tests (land and water). Therefore, it can be concluded that the eggbeater kick test is a specific and valid protocol to asses $\mathrm{VO}_{2 \text { max }}$ in water polo players.
\end{abstract}

Keywords: water polo, oxygen uptake, assessment

\section{Introduction}

Water polo is an invasion sport played with two teams of thirteen players each, consisting of seven fielders and six reserves ${ }^{1,2}$. One common technique used by water polo players include the eggbeater kick, which is a propulsive movement of the lower limbs, also used in synchronized swimming ${ }^{3}$. The skill required in the eggbeater kick in water polo allows the players to (1) remain in the vertical position, (2) receive or execute a pass, (3) shoot for a goal, (4) move in the field, (5) block the opponent, and (6) use the upper body to move upward ${ }^{4,5}$. Specifically, it is a movement of cyclical action performed by the hips, knees, and ankles, with the movements of the right and left lower limbs in opposite directions in the cycle. Hips, knees, and ankles move in an inverse circular direction, i.e., the left leg moves clockwise and the right counter-clockwise ${ }^{3}$. During a match, the players perform the eggbeater kick when in a vertical position. Analyses of water polo matches indicated that the total time spent in the vertical position ranges between 55 and $66.9 \%$ of the match ${ }^{6-8}$.

In order to perform any type of sport or activity, it is necessary to use energy which comes from different metabolic pathways. Among the assessments of metabolic capabilities, the maximal oxygen uptake $\left(\mathrm{VO}_{2 \max }\right)$ is considered a good indicator of the ability of a person to perform a task. The $\mathrm{VO}_{2 \max }$ correct identification is critical in performance analysis for further prescription and for appropriate training ${ }^{9}$. According to Aleksandrovič ${ }^{10}$, there is a paucity of information regarding physiological capacity and specific motor skills, such as eggbeater kick, of the players. One possible reason for this may be due to the difficulties imposed by the aquatic environment in obtaining appropriate physiological parameters, such as the $\mathrm{VO}_{2 \max }$.

Usually the $\mathrm{VO}_{2 \max }$ is identified in tests performed on treadmills, cycle ergometers, or other equipment that allows for control of the load imposed on the subject assessed. In general, several protocols are used to ensure the results are valid, objective, and reproducible ${ }^{9,11}$. However, specific protocols to assess the $\mathrm{VO}_{2 \max }$ in water polo players, performing the eggbeater kick, have not being found, except those used in swimming tests ${ }^{12}$. Specifically, Lobenius ${ }^{13}$ compared a maximum eggbeater kick test and cycle ergometer test to investigate the validity of a newly developed eggbeater kick test in eight synchronized swimming athletes $(20.8 \pm 3.4$ years; $62.3 \pm$ $6.2 \mathrm{~kg} ; 9.4 \pm 5.0$ years training). During the eggbeater kick test, the athletes: (a) used both arms for sculling; (b) kept their shoulders above the surface; (c) wore a diving belt where the load increased every 30 seconds; and (d) had their $\mathrm{VO}_{2}$ measured every $15 \mathrm{sec}$ onds. The $\mathrm{VO}_{2 \text { peak }}$ was higher during the eggbeater kick test when compared with the cycle ergometer test and the range of differences between the two tests was large. Furthermore, there was correlation between the tests. It was concluded that the eggbeater kick test could also be a specific test for synchronized swimmers, which enables them technically, physiologically, and psychologically to reach higher values during the test. Nevertheless, there is not information for both tests in reference to load, cadence, and exhaustion time in Lobenius's study ${ }^{13}$.

Therefore, the aim of this study is to compare and to verify the agreement between two different maximal protocol tests in water polo players.

\section{Methods}

This study included twelve water polo state/recreational level players with a minimum of two years' experience in the sport. The players were training normally two to three times per week for 90 minutes during the test period. All participants 
were informed about the objectives and protocols of this study through a Term of Consent. This study was approved by the Ethics Committee of the University where the study was conducted (22286613100005347).

The cycle ergometer test was performed in the laboratory (room temperature controlled and maintained at $21^{\circ} \mathrm{C}$ ) and the eggbeater kick test in a $25 \mathrm{~m}$ swimming pool ( $1.90 \mathrm{~m}$ deep, heated water temperature of approximately $29^{\circ} \mathrm{C}$ ) during the players' training season. The procedures were divided into two phases:

\section{First Phase}

Each player was received in the laboratory where the characteristics of the sample were obtained (wearing shorts and t-shirt): water polo time experience, match position, age, and anthropometric data (skin folds, weight, and height). The physiological variables were measured $\left(\mathrm{VO}_{2}, \mathrm{RER}, \mathrm{HR}\right.$ and IEP) at rest, and after standing in an upright position for five minutes. Next, the player warmed-up on a cycle ergometer for five minutes at a cadence of 70-80 RPM and load of $50 \mathrm{~W}$, when HR and IEP were measured. The maximal cycle ergometer test was a progressive protocol with an initial workload of $100 \mathrm{~W}$ and increments of $25 \mathrm{~W} /$ minute until exhaustion, the cadence was maintained between 70-80 RPM. This test protocol has been used for cyclists and triathletes in many previous studies ${ }^{14-16}$. Exhaustion was identified when the players could not maintain the minimum cadence (70 RPM) or by ending the test voluntarily. In the cycle ergometer test, $\mathrm{VO}_{2}$, RER, and $\mathrm{HR}$ were measured every minute and IEP was measured in the last 15 seconds of every minute.

\section{Second Phase}

After a minimum of 48 hours from the completion of the first phase, the second phase was performed in the swimming pool. The player, wearing the usual sport speedo, performed the progressive protocol in eggbeater kick. Initially, the physiological variables $\left(\mathrm{VO}_{2}, \mathrm{RER}, \mathrm{HR}\right.$ and IEP) were measured at rest after five minutes in a standing position, and subsequently also at rest by standing upright in the water for five minutes on a pool deep reducer to further investigate the possible effects of immersion on the variables. On the pool deep reducer, the player maintained the water surface between xiphoid process and shoulders. The player then warmed-up for five minutes performing a low-intensity eggbeater kick with both hands in a sculling motion. Following the warm up, the player left the pool to place two adhesive tape marks (approximately $4 \mathrm{~cm}^{2}$ each) on the acromion process on each shoulder, and to put on the load belt (in the belt there were four pockets, two in front and two in the back for load placement). The second phase test consisted of the player performing the eggbeater kick while maintaining the shoulder marks on the water surface. During the test, the player performed with one arm in sculling and the other held outside of the water. The player could freely choose which arm, but could not change arms during the test.
The maximum eggbeater kick test was a progressive protocol beginning with a $1 \mathrm{~kg}$ load and every minute it was increased by $0.5 \mathrm{~kg}$ until exhaustion. $\mathrm{VO}_{2}$, RER, and HR were measured continuously throughout the test. The IEP was collected in the last 15 seconds of every minute. To identify the test cadence, a trained researcher used a manual chronometer (Seiko S140, resolution de 1/100) to control the cycles of eggbeater kick. The cadence was measured in seconds: how long each player performed six complete cycles of eggbeater kick in the last 15 seconds of every minute. Then, the number of cycles (6) was divided by the measured time, and the result was transformed into cycles per minute. The technical criteria suggested by Homma and Homma ${ }^{4}$ for the eggbeater kick's performances (keep the highest knees possible and near the surface of the water, keep the heel closest the hip) were controlled. The exhaustion level was identified when the player could not maintain the shoulder marks on the water surface or by voluntarily ending the test.

\section{$\mathrm{VO}_{2}$ and $\mathrm{RER}$ in phases 1 and 2}

$\mathrm{VO}_{2}$ and RER were directly measured using a mixingbox-type portable gas analyzer VO2000 ${ }^{2}$ (Portable Metabolic Testing System, Medgraphics, Ann Arbor, USA). Instrument calibration was performed before each assessment according to the manufacturer's specifications. The expired gas concentrations were measured breath by breath and all of the records followed the method of average breathing rate of three respiratory cycles. The data were transferred to a computer via the Aerograph software and exported to Excel for analysis. The neoprene mask was used in both phases to block breathing from the nose. Next, individual curves between load and $\mathrm{VO}_{2}$ and RER were plotted. RER was calculated from the obtained $\mathrm{O}_{2}$ and $\mathrm{CO}_{2}$ data. The $\mathrm{O}_{2}$ analyzer type was the Galvanic Fuel Cell (range: $0-96 \%$, accuracy: $\pm 0.1 \%$ ), and the $\mathrm{CO}_{2}$ analyzer was Non-Dispersive Infrared (range: $0-10 \%$, accuracy: $\pm 0.2 \%$ ). As it was not possible to identify a plateau in $\mathrm{VO}_{2}$ behavior, in most of the players, $\mathrm{VO}_{2}$ peak $\left(\mathrm{VO}_{2 \text { peak }}\right)$ was used as criteria for $\mathrm{VO}_{2}$ ${ }_{\text {max }}$. Therefore, the average was calculated of the two highest $\mathrm{VO}_{2 \text { peak }}$ values identified during the test on the same workload. The associated values of RER of these $\mathrm{VO}_{2}$ values were also considered maximum values. During the land-resting (phases 1 and 2) and the water-resting (phase 2), the players stood upright for five minutes close to the metabolic gas analyzer. The measurement of metabolic variables began during the last minute in the resting position. The determination of the absolute values of $\mathrm{VO}_{2}\left(1 \cdot \mathrm{min}^{-1}\right)$, and relative to body mass $\left(\mathrm{ml} \cdot \mathrm{kg}^{-1} \cdot \mathrm{min}^{-1}\right)$ were given after the elimination of dead space, defined as the average of the values collected during the remaining period $(1 \mathrm{~min})$.

\section{IEP and HR in Phases 1 and 2}

The players performed two familiarization sessions with the scale 6-20 point of the Borg ${ }^{17}$ prior to the application of the protocols of this study. Prior to the trial, during training, in order to familiarize the players, the scale was presented to the 
subjects in exercises at different intensities and distances, and then the subject assigned a numerical value of the corresponding scale of the IEP at the requested time. To measure the HR values at rest (last minute), warm up (pre-test, last minute), during testing (every minute), and post-test in phases 1 and 2, a Polar Electro ${ }^{\circledR}$ (Finland) Model Polar FT1 heart monitor was used. The maximal heart rate $\left(\mathrm{HR}_{\text {max }}\right)$ of each player was defined as the highest value achieved in both tests. Then, the HR ${ }_{\text {max }}$ was considered as: (1) 220 minus age (years) to the test on a cycle ergometer, and (2) 220 minus age and minus the individual value of bradycardia, identified by subtraction between the land-resting heart rate, and the water-resting heart rate for the eggbeater test (phase 2).

\section{Statistical Analysis}

The Shapiro-Wilk test was used to verify the normality of the data. Means, standard deviations, and coefficients of variation were calculated. Comparisons between the maximum values of the variables obtained from both tests (land and water) were performed with the Student's t-test for paired data. The comparison between the land rest (phases 1 and 2) and the water rest (phase 2), and the comparison between cadences throughout the test in the water were performed with ANOVA for repeated measures; in this case the sphericity of the data was verified (Mauchly test). When necessary, and indicated by the degrees of freedom in the Fischer test results the Greenhouse-Geisser Epsilon Correction Factor was used. The main effects were tested with Bonferroni post hoc; statistical power was calculated and the effect size was verified with statistical eta ${ }^{2}$. The comparison between the eggbeater kick test cadences and the cycle ergometer test fixed cadences was performed with $t$ Student simples test (cycle ergometer fixed value cadences were 70-80 RPM). The Intraclass Correlation (ICC) values between both tests outcomes were calculated.

Between the maximum loads reached in the cycle ergometer test (W) and the eggbeater kick test $(\mathrm{kg})$, a Pearson linear correlation test was conducted. In order to verify the agreement between the values obtained from both tests, the Bland-Altmann graphical analysis was performed with the calculation of bias and limits of agreement. The significance level was $\alpha \leq 0.05$ and the SPSS statistical package (15.0) was used for all the analyses.

\section{Results}

Twelve state-level, recreational water polo players volunteered to take part in this study; characteristics of the sample are shown in Table 1.

Table 1. General characteristics of the sample, mean \pm standard deviation $(S D) ; \mathrm{n}=12$.

\begin{tabular}{cccccc}
\hline & $\begin{array}{c}\text { Age } \\
\text { (years) }\end{array}$ & $\begin{array}{c}\text { Body mass } \\
\text { (kg) }\end{array}$ & $\begin{array}{c}\text { Height } \\
\text { (cm) }\end{array}$ & $\begin{array}{c}\sum \text { cutaneous } \\
\text { folds }(\mathbf{m m})\end{array}$ & $\begin{array}{c}\text { Experience } \\
\text { time (years) }\end{array}$ \\
\hline Mean & 30,5 & 79,2 & 179,7 & 179,7 & 10 \\
$S D$ & 7,7 & 7,2 & 5,9 & 5,9 & 7,7 \\
\hline
\end{tabular}

Resting $\mathrm{VO}_{2}$, RER, $\mathrm{HR}$, and IEP in three situations: land-resting in phase 1 (pre-test in the cycle ergometer); land-resting in phase 2 (pre-test in the eggbeater kick); and water-resting in phase 2 (pre-test in the eggbeater kick) in means, $S D$, and coefficients of variation are shown in Table 2. In comparison of the resting values (Table 2 ) in the three situations, effects of immersion were evident only in the resting $\operatorname{HR}\left(\mathrm{F}_{2,22}=5.11 ; p\right.$ $=0.015$ eta $^{2}=0.317$, power $\left.=0.766\right)$ with lower values in the water-resting (phase 2) compared to land-resting (phase 2). The bradycardia was identified in average of $9.7 \pm 5.2 \mathrm{bpm}$.

Table 2. Means, standard deviation, and coefficients variation of oxygen uptake $\left(\mathrm{VO}_{2}\right)$, respiratory exchange ratio (RER), heart rate (HR), the perceived exertion index (IEP) in resting in pre-cycle ergometer test, and pre-eggbeater kick test (land and water); $\mathrm{n}=12$.

\begin{tabular}{cccc}
\hline & $\begin{array}{c}\text { Cycle ergometer } \\
\text { Land-resting }\end{array}$ & $\begin{array}{c}\text { Eggbeater kick } \\
\text { Land-resting }\end{array}$ & $\begin{array}{c}\text { Eggbeater kick } \\
\text { Water-resting }\end{array}$ \\
\hline $\mathrm{VO}_{2}(\mathrm{ml}$. & $3.7 \pm 1.4$ & $3.9 \pm 0.8$ & $4.2 \pm 1.1$ \\
$\left.\mathrm{~kg}^{-1} . \mathrm{min}^{-1}\right)$ & $(38.7 \%)$ & $(20.9 \%)$ & $(27.9 \%)$ \\
$\mathrm{RER}$ & $0.92 \pm 0.13$ & $0.96 \pm 0.09$ & $0.98 \pm 0.09$ \\
& $(14.8 \%)$ & $(9.3 \%)$ & $(9.7 \%)^{\#}$ \\
$\mathrm{HR}(\mathrm{bpm})$ & $74.3 \pm 14.0$ & $80 \pm 9.2 *$ & $70.2 \pm 11.8^{*}$ \\
& $(18.9 \%)$ & $(11.5 \%)$ & $(16.8 \%)$ \\
$\mathrm{IEP}$ & $6.25 \pm 0.4$ & $6 \pm 0$ & $6.08 \pm 0.2$ \\
(points) & $(7.2 \%)$ & $(0 \%)$ & $(4.7 \%)$ \\
\hline
\end{tabular}

\#this case $\mathrm{n}=9 ;{ }^{*} p=0,019$.

Means, $S D$, and coefficients of variation of $\mathrm{VO}_{2 \max }, \mathrm{RER}$, $\mathrm{HR}_{\max }, \mathrm{IEP}_{\max }$, achieved from load and exhaustion time from the cycle ergometer test and eggbeater kick test are shown in Table 3. There were no differences between the maximum values of the two tests. It is assumed that $\mathrm{VO}_{2 \max }$ had been reached in both (in land and water) protocols (although identified by the $\mathrm{VO}_{2 \text { peak }}$ ) according to the criteria established by Howley ${ }^{18}$ : the percentage of the estimated maximum heart rate reached $\geq 90 \%$; high value for respiratory exchange ratio, and perceived exertion index for the players reported the maximum effort. The cycle ergometer test and eggbeater kick test HR ${ }_{\text {max }}$ achieved, respectively, 95.7 $\pm 5.9 \%$ and $99.9 \pm 7.7 \%$ of the estimated HR max . The Intraclass Correlation Coefficient (ICC) calculated for $\mathrm{VO}_{2 \max }, \mathrm{RER}, \mathrm{HR}$ max , and exhaustion time were, respectively, $0.097(p=0.43)$, $0.007(p=0.50), 0.948(p<0.001)$, and $0.419(p=0.091)$.

There was no correlation between the maximum loads achieved in both tests. In relation to the eggbeater kick test cadence, considering that there is a need to increase the movement frequency while the load was increased, Figure 1 shows the cadence in cycles per minute for three periods of the test (beginning, middle, and end). There was a significant increase in the movement frequency from the beginning to the end of the test $\left(\mathrm{F}_{1.39 ; 14.5}=32.2, p<0.001\right.$; eta $^{2}=0.746$; power $\left.=1.0\right)$. The cycle ergometer test cadence was fixed at 70-80 RPM (permissible cadence range of this test). When comparing the beginning, middle, and end of the eggbeater kick and cycle ergometer test cadence, the eggbeater kick cadence was higher than 70 RPM in all periods (beginning: $\mathrm{t}_{11}=2.4 ; p=0.035$; middle: $\mathrm{t}_{11}=4.2 ; p=0.001$; and end: $\left.\mathrm{t}_{11}=7.2, p<0.001\right)$. The eggbeater kick cadence in the beginning and the middle were 
similar to the cycle ergometer cadence of 80 RPM, while the cadence at the end was higher $\left(\mathrm{t}_{11}=3.2 ; p=0.007\right)$.

Table 3. Mean, standard deviation, and coefficients variation of maximum oxygen uptake $\left(\mathrm{VO}_{2 \max }\right)$, maximum respiratory exchange ratio $\left(\mathrm{RER}_{\max }\right)$, maximum heart rate $\left(\mathrm{HR}_{\max }\right)$, maximum perceived exertion index $\left(\operatorname{IEP}_{\max }\right)$, achieved load, and the exhaustion time in cycle ergometer and eggbeater kick tests; $\mathrm{n}=12$.

\begin{tabular}{|c|c|c|}
\hline & Cycle ergometer test & Eggbeater kick test \\
\hline 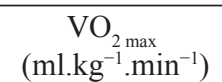 & $\begin{array}{c}40.2 \pm 2.7 \\
(6.9 \%)\end{array}$ & $\begin{array}{c}38.4 \pm 5.7 \\
(14.1 \%)\end{array}$ \\
\hline $\mathrm{RER}_{\max }$ & $1.17 \pm 0.08(6.8 \%)$ & $1.19 \pm 0.12(10.1 \%)$ \\
\hline $\mathrm{HR}_{\max }(\mathrm{bpm})$ & $181.4 \pm 11.7(6.5 \%)$ & $179 \pm 11.7(5.8 \%)$ \\
\hline $\mathrm{IEP}_{\max }$ (points) & $20 \pm 0(0 \%)$ & $20 \pm 0(0 \%)$ \\
\hline $\begin{array}{c}\text { Achieved } \\
\text { load }\end{array}$ & $\begin{array}{c}304.1 \pm 29.8 \mathrm{~W} \\
(9.7 \%)\end{array}$ & $\begin{array}{c}4.9 \pm 1.03 \mathrm{~kg} \\
(21.0 \%)\end{array}$ \\
\hline $\begin{array}{l}\text { Exhaustion time } \\
\text { (min) }\end{array}$ & $\begin{array}{l}8.7 \pm 1.3 \\
(14.9 \%)\end{array}$ & $\begin{array}{l}8.1 \pm 1.9 \\
(23.4 \%)\end{array}$ \\
\hline
\end{tabular}

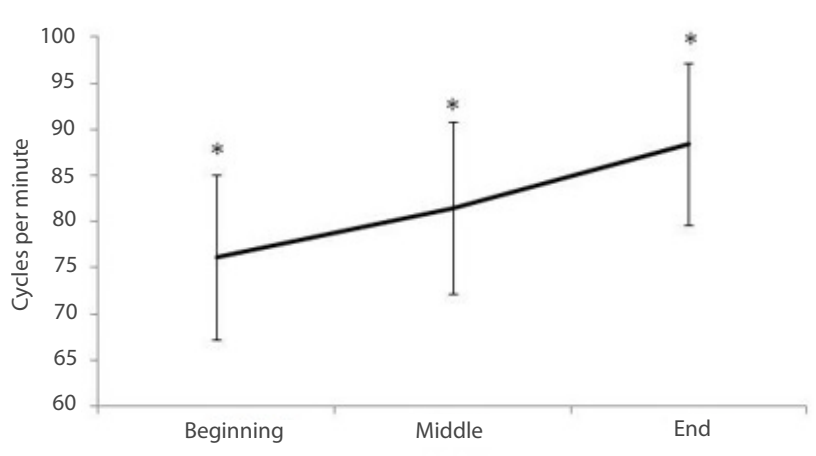

Eggbeater Test Periods

Figure 1. Eggbeater kick test cadence in cycles per minute in three periods (beginning, middle, end); $\mathrm{n}=12 ; * p<0.01$ for all comparison

Bland-Altmann graphical analysis, as shown in Figures 2, 3, and 4, illustrate the limits of agreement between the tests. $\mathrm{VO}_{2}$ (Bias: 1.74; limits of agreement: $-10.40 ; 13.87)$, RER (Bias: -0.02 ; limits of agreement: $-0.30 ; 0.26$ ), and $\mathrm{HR}_{\max }$ (Bias: 2.41 ; limits of agreement: $-7.31 ; 12.14)$. Bland-Altmann analyses indicate acceptable limits of agreement in the three variables. The data obtained from the two tests are considered to be in agreement as they fall within the established limits of agreement.

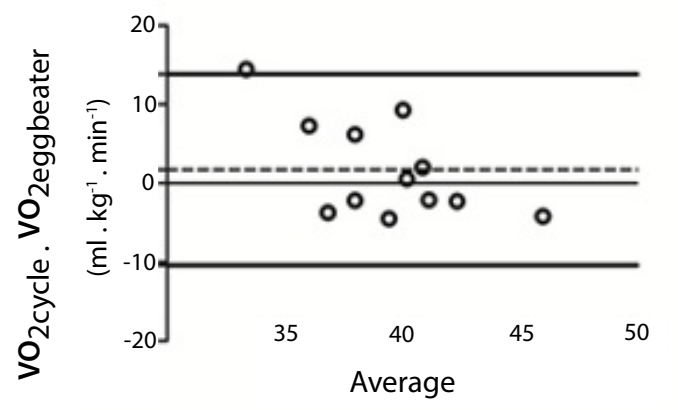

--- Bias $(1,74)$

- 95\% Limits of Agreement $(-10,40 ; 13,87)$

Figure 2. $\mathrm{VO}_{2}$ values' Bland-Altmann analyses.

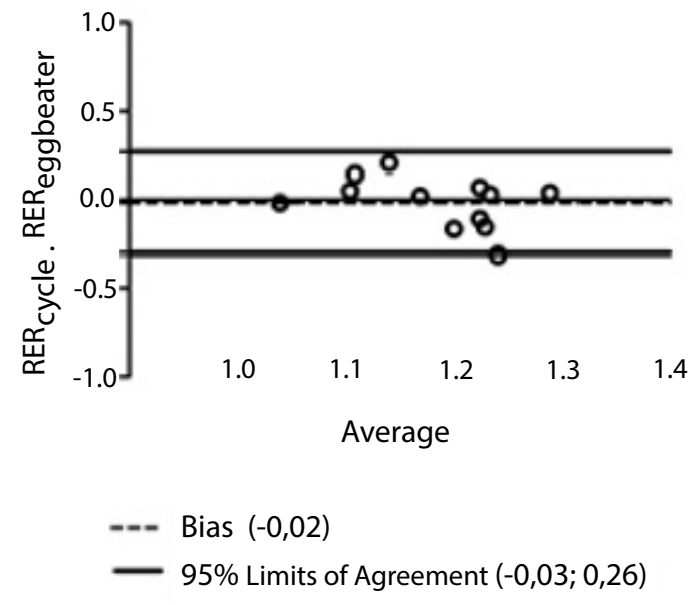

Figure 3. RER's Bland-Altmann analyses.

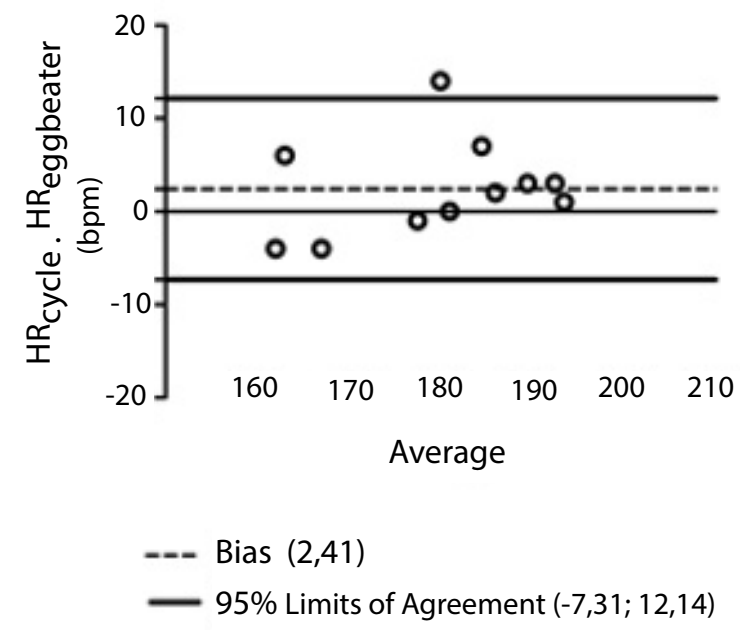

Figure 4: HR's Bland-Altmann analyses.

\section{Discussion}

Considering the specifics of water polo, especially the eggbeater kick technique, and its importance for sport performance, this study aimed to compare and to verify the agreement between water polo players' $\mathrm{VO}_{2 \max }$ values obtained from two different protocol tests: one test performed on a cycle ergometer (land), and another test in eggbeater kick (water). In general, no differences were evident between the protocols for all analyzed parameters, low values of Intraclass Correlation Coefficient (exception for the $\mathrm{HR}_{\mathrm{max}}$ ), and acceptable agreement results.

The sample characteristics of this study indicate that the participants have lower stature and body mass values than top level players. ${ }^{8,12,19}$ These results, in addition to prior knowledge of the assessed players, confirm that the participants of this pilot study are not elite players. Indeed, based on their time spent in training (2-3 times per week for a period of 90 minutes each), and their involvement in regional-level championships, they are considered 
to be recreational players. These characteristics become relevant for the analyses of $\mathrm{VO}_{2 \max }$ values identified in this study.

Possible immersion effects are concern regarding effort tests in an aquatic environment. However, the $\mathrm{VO}_{2}$ and RER values did not change during the immersion period in this study. Similarly, a previous study compared seven men at rest and during exercise on a cycle ergometer in two situations: land and water ${ }^{20}$. Significant statistical differences were found between the two situations (land $\mathrm{VO}_{2}: 3.87 \mathrm{ml} \cdot \mathrm{kg}^{-1} \cdot \mathrm{min}^{-1}$; at rest: $35 \mathrm{ml} \cdot \mathrm{kg}^{-1} \cdot \mathrm{min}^{-1}$; water $\mathrm{VO}_{2}: 3.88 \mathrm{ml} \cdot \mathrm{kg}^{-1} \cdot \mathrm{min}^{-1}$; and cycle ergometer: $\left.36 \mathrm{ml} \cdot \mathrm{kg}^{-1} \cdot \mathrm{min}^{-1}\right)$. The immersion effect on HR was visible and the results of this study are consistent with the literature regarding immersion bradycardia ${ }^{21-23}$. Specifically, the bradycardia effect averaged $9.7 \pm 5.2 \mathrm{bpm}$. In an aquatic environment, the condition of resting or exercise changes HR, and it is influenced by factors, such as body position, the immersion depth, and the water temperature ${ }^{24}$. The immersion allowed greater hydrostatic pressure which facilitated the venous return that consequently maintains the same cardiac output, reducing $\mathrm{HR}$, and therefore, explains the bradycardia.

The average $\mathrm{VO}_{2 \max }$ values in both tests showed lower values when compared with values proposed in the literature ${ }^{8,25}$. Most likely, this fact is due to the sample of this study: recreational-level water polo players. The $\mathrm{VO}_{2 \max }$ values described in the literature for elite water polo players with a high-volume and intensity level of training, range between 58 and $63 \mathrm{ml} . \mathrm{kg}^{-1}$. $\min ^{-1}$, but these values depend on the study and the type of protocol used. The most frequent protocol found in the literature is swimming tests ${ }^{8,25}$. Among the findings, Tsekouras ${ }^{12}$ found $\mathrm{VO}_{2 \text { peak }}$ values of $57.9 \pm 7.0 \mathrm{ml} \cdot \mathrm{kg}^{-1} \cdot \mathrm{min}^{-1}$ in a maximum test of $400 \mathrm{~m}$ front crawl for water polo players. These values are similar to those found by Zacca ${ }^{26}$ with swimmers using the same distance and the same method $\left(63.5 \pm 8.7 \mathrm{ml} \cdot \mathrm{kg}^{-1} \cdot \mathrm{min}^{-1}\right)$. Although water polo requires swimming, less than $40 \%$ of match time is spent swimming. In fact, most of the matches' time is spent in a vertical position performing the eggbeater kick; therefore, it is more appropriate to test water polo players while performing the eggbeater kick than swimming.

During the cycle ergometer test, the cadence was fixed between 70-80 RPM. In the eggbeater kick test when the load was increased, cadence was increased as well. However, the average cadence in both tests was similar in the majority of periods; the exception was the eggbeater test's end, when the players increased the eggbeater kick cadence more than 80 cycles per minute in order to keep the shoulders above the surface of the water under maximum load. Differences in cadence between the tests could be attributed to a limitation of comparison between them, mostly due to the different strategies of motor unit recruitment under different levels of cadence.

The variability between the results in the eggbeater kick test was higher than in the cycle ergometer test, probably, due to the differences in kinetic and kinematic parameters of the feet in these environments (land and water). Alberton ${ }^{27}$ did not find differences in $\mathrm{VO}_{2 \max }$ and IEP between treadmill tests (land) when compared to three different water aerobic exercises (water). The $\mathrm{VO}_{2 \max }$ data variability of this study could be related to the involved muscle mass during the exercises, rather than the environment in which the individual is exercising. Moreover, as the players are accustomed to training with regard to the eggbeater kick in all sessions, the progressively increased load could lead to increased variability of the task execution, that is, individual strategies of active muscle mass recruitment may be reflected in greater variability in metabolic variables of a water test.

The specific analysis of the results of correlation and agreement, when associated with the comparison results, lead to the first objective of this project:

(1) Correlation was not found between the maximum load of the cycle ergometer test (WATTS) and the maximum load of the eggbeater kick test $(\mathrm{kg})$; this result can be explained by the specifics of both gestures and the responses of the loads;

(2) Low values of ICC indicate poor intraclass correlation, which could be explained by both the level of the athletes and differences between the assessed motor tasks;

(3) the Bland-Altmann analysis indicated agreement, i.e., the cycle ergometer test values (land) agree with the eggbeater kick test values (water), within reasonable agreement limits. The bias values represented, respectively, for the eggbeater kick test data in $4.5 \% \mathrm{VO}_{2 \max } ; 10 \% \mathrm{RER}$, and $1.34 \% \mathrm{HR}_{\max }$.

Therefore, such findings support the argument that the maximal oxygen uptake can be estimated in a progressive test in the eggbeater kick for water polo players with an error margin of $4.5 \%$. This test is specific to the practiced gesture in water polo matches and respects the particularities of the aquatic environment. The different tests used by coaches and the lack of a specific and valid test makes it difficult to use and provide consistent interpretation of $\mathrm{VO}_{2 \mathrm{~m}}$ values found for water polo players. Tests using objective physiological measurements, often based on laboratory testing protocols, can be used to form a basis for a valid and reliable specific test for this sport. ${ }^{8}$ Therefore, this study was designed for the specific test for water polo, using a laboratory test as a base.

\section{Conclusion}

The results of the progressive protocol performed with the water performing eggbeater kick did not differ, and it presented agreement with the results obtained on land on the cycle ergometer, although low ICC values were found. More studies on this topic, beyond this pilot, with larger samples and higher-level water polo players, would aid to further understand the possibility of applying the eggbeater protocol to asses $\mathrm{VO}_{2 \max }$.

\section{References}

1. Lamas L. Barrera J, Otranto G, Ugrinowitsch C. Invasion team sports: strategy and match modeling. Int J Perform Analysis Sport. 2014; 14 (1):307-29.

2. Snyder P. Water Polo for Players \& Teachers of Aquatics. California. LA84 Fondation. USA, 2008. Available from: http:// www.la84foundation.org (accessed on January 5 2015).

3. Platanou T. On-water and dryland vertical jump in water polo players. J Sports Med Physical Fitness. 2005; 45: 26-31. 
4. Homma M, Homma M. Coaching points for the technique of the eggbeater kick in synchronized swimming based on three-dimensional motion analysis. Sports Biomechanics. 2005; 4 (1):73-88.

5. Sanders R. Strength, flexibility and timing in the eggbeater kick. Available from: http://www.coachesinfo.com (accessed on January 5 2015).

6. Dopsaj M, Aleksandrovic M. Basic anthropomorfological characteristics of elite senior Serbian water polo players according to field position. Int J Fitness. 2009; vol. 5 (2).

7. Dopsaj M, Thanopoulos V. The structure of evaluation indicators of vertical swimming work ability of top water polo players. Rev Port Ciencias Desporto. 2006; 6 (2):124-26.

8. Smith HS. Applied Physiology of water polo. Sports Med. 1998; 26 (5):317-34.

9. Wilmore JH, Costill DL. Fisiologia do Esporte e do Exercício. Editora Manole LTDA, $1^{\circ}$ edição brasileira, Barueri/SP, 2001.

10. Aleksandrovic M. Functional abilities as a predictor of specific motor skills of young water polo players. J Human Kinetics. 2011; 29: 123-32.

11. Ferreti G. Maximal oxygen consumption in healthy humans: theories and facts. Eur J Appl Physiol. 2014; 114:2007-2036.

12. Tsekouras YE, Kavouras SA, Campagna A, Kotsis YP, Syntosi SS, Papazoglu K et al. The anthropometrical and physiological characteristics of elite water polo players. Eur J Appl Physiol, 2005; 95 (1): 35-41.

13. Lobenius K. Physiological differences during exercise in water and on cycle ergometer for synchronized swimmers. In: Biomechanics and Medicine in Swimming, França. 2002; IX: 539-544.

14. Lucia A, Hoyos J, Perez M, Santalla A, Chicharro JL. Inverse relationship between $\mathrm{VO} 2 \mathrm{max}$ and economy/efficiency in worldclass cyclist. Med Sci Sports Exerc. 2002; 34(12):2079-84.

15. Bini RR, Senger D, Lanferdini F, Lopes AL. Joint kinematics assessment during cycling incremental test to exhaustion. Isokinetics Exerc Sci. 2012; 20: 99-105.

16. Bini R. Hume PA, Lanferdini FJ, Vaz MA. Effects of body positions on the saddle on pedalling technique for cyclists and triathletes. Eur J Sport Sci. 2014; 14(S1): S413-S420.

17. Borg G. Psychophysical bases of perceived exertion. Med Sci Sports Exerc. 1982; 14 (5):377-81.

18. Howley ET, Basset DR, Welch HG. Criteria for maximal oxygen uptake: review and commentary. Med Sci Sports Exerc. 1995; 27: 1292-1301.

19. Dopsaj M. Pulling force characteristics of $10 \mathrm{~s}$ maximal tethered eggbeater kick in elite water polo players: a pilot study. Biomechanics Med Swimming. 2010; XI: 69-71.

20. Nagashima K, Hose H, Yoshida T, Morimoto T. Relationship between atrial natriuretic peptide and plasma volume during graded exercise with water immersion. J Appl Physiol. 1995; 78 (1): $217-24$.
21. Hall J, Grant J, Blake D, Taylor G, Garbutt G. Cardiorespiratory responses to aquatic treadmill walking in patients with rheumatoid arthritis. Physiother Res Int. 2004; 9:59-73.

22. Kruel LFM. Peyre-Tartaruga LA,Alberton CL, Muller FG, Petkowizc R. Effects of hydrostatic weight on heart rate during immersion in water. Aquatic Fitness Res J. 2004; 1: 1 - 4.

23. Tiggemann CL, Guedes MG, Bgeginski R, Pinto RS, Kruel LFM. Comparação de variáveis cardiorrespiratórias máximas entre a corrida em piscina funda e a corrida em esteira. Motriz. 2007; 13 (4):266-72.

24. Graef FI, Kruel LFM. Frequência cardíaca e percepção subjetiva do esforço no meio aquático: diferenças em relação ao meio terrestre e aplicações na prescrição do exercício - uma revisão. Rev Bras Med Esporte. 2006; 12: $\mathrm{n}^{\circ} 4$.

25. Platanou T. Physiological demands of water polo goalkeeping. J Sci Med Sport. 2009; 12: 244-50.

26. Zacca R, Teixeira BC, Lopes AL, Matos CC, Engelmann L, Castro FAS. $\mathrm{VO}_{2}$ assessed by backward extrapolation in 200, 400, 800, and $1500 \mathrm{~m}$ front crawl in youth swimmers. In: XII International Symposium on Biomechanics and Medicine in Swimming, 2014, Canberra. Proceedings of the XII International Symposium on Biomechanics and Medicine in Swimming. Canberra: Australian Institute of Sport. 2014; 1: 531-36.

27. Alberton CL, Antunes AH, Beilke DD, Pinto SS, Kanitz AC, Tartaruga MP, Martins Kruel LF. Maximal and ventilatory thresholds of oxygen uptake and rating of perceived exertion responses to water aerobic exercises. J Strength Cond Res. 2013;27(7):1897-903.

\section{Corresponding author}

Ligia Ignez Engelmann

Grupo de Pesquisa em Esportes Aquáticos, ESEF, Universidade Federal do Rio Grande do Sul, Rua Felizardo, 750, Bairro Jardim Botânico, Porto Alegre/RS, Brazil. Email: ligia.engel@gmail.com

Manuscript received on February 29, 2016

Manuscript accepted on April 10, 2016

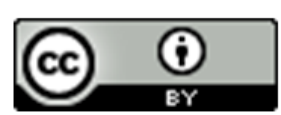

Motriz. The Journal of Physical Education. UNESP. Rio Claro, SP, Brazil - eISSN: 1980-6574 - under a license Creative Commons - Version 3.0 